\title{
Feasibility Study of Azo Dye Treatment by Decolorized Metabolites-Assisted Salt-Bearing Microbial Fuel Cells
}

\author{
Pei-Lin Yueh, Bor Yann Chen*, Chung Chuan Hsueh \\ Department of Chemical and Materials Engineering, National I-Lan University, I-Lan, Taiwan, R.O.C.
}

\section{Email address:}

j93070534@yahoo.com.tw (Pei-Lin Yueh), boryannchen@yahoo.com.tw (Bor Yann Chen), bychen@ms.niu.edu.tw (Bor Yann Chen), cchsueh88@gmail.com (Chung Chuan Hsueh)

*Corresponding author

\section{To cite this article:}

Pei-Lin Yueh, Bor Yann Chen, Chung Chuan Hsueh. Feasibility Study of Azo Dye Treatment by Decolorized Metabolites-Assisted Salt-Bearing Microbial Fuel Cells. Science Discovery. Vol. 4, No. 2, 2016, pp. 99-108. doi: 10.11648/j.sd.20160402.18

Received: February 29, 2016; Accepted: May 5, 2016; Published: May 18, 2016

\begin{abstract}
Prior findings mentioned that $-\mathrm{OH}$ and $-\mathrm{NH}_{2}$ substitute-containing auxochrome compounds (e.g., 2-aminophenol and 1,2-dihydroxybenzene) could act as electron shuttles (ESs) for simultaneous dye decolorization and bioelectricity generation (DD\&BG) in microbial fuel cells (MFCs). This feasibility study used decolorized intermediates (DIs) of reactive blue 171, reactive blue 5, reactive red 198 to show such significant electron-shuttling capabilities. Cyclic voltammetric inspections clearly revealed that some of DIs could act as ESs to enhance dye-decolorizing and bioelectricity-generating capabilities without dispute. However, electron transfer (ET) efficiency significantly reduced ca. 40\% at higher salt conditions. With supplementation of DIs, ET efficiency was apparently augmented for highly efficient DD and BG. Meanwhile, significant stimulation of ET characteristics also overcame osmotic pressure-gradients between intracellular and extracellular compartments for promising DD and BG. Accumulation of DIs was kinetically favorable for expression of dye-decolorizing capabilities. Of course, such accumulation of DIs autocatalytically enhanced DD and MFC-assisted treatment was technically appropriate for ET-based bioremediation.
\end{abstract}

Keywords: Electron Shuttles, Textile Dyes, Bioelectricity Generation, Microbial Fuel Cells, Decolorized Intermediates

\section{染料中間物輔助微生物燃料電池染料脫色處理之可行性評估}

\author{
岳沛林, 陳博彥*, 薛仲娟 \\ 化學工程與材料工程學系, 國立宜蘭大學, 宜蘭, 台灣
}

\begin{abstract}
郵箱
j93070534@yahoo.com.tw（岳沛林）, boryannchen@yahoo.com. tw, bychen@ms.niu. edu. tw（陳博彥）, cchsueh88@gmail. com（薛仲娟）
\end{abstract}

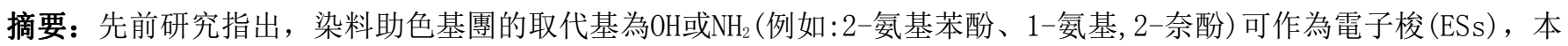
研究使用染料中間物推測出之模式芳香胺中間物, 用來刺激含染料廢水脫色及生物產電之可能性。研究並探討 “脫色 中間物之實際效率” (例如: 活性藍171號 (Reactive Blue 171)、活性黑5號 (Reactive Black 5)、活性紅198號 (Reactive Red 198) 活性紅141號 (Reactive Red 141) 之脫色產物是否亦具有明顯電子梭的能力。循環伏安圖譜指出部分偶氮染 料脫色中間物具有電子梭之能力, 添加於微生物燃料電池可促進其脫色效果及產電效能, 研究結果顯示, 在高鹽條件 下，電子轉移效率明顯下降約 $40 \%$; 在加入具有電子梭特性之脫色代謝物, 確實可大大提高電子轉移效率, 利於脫色及 產電。同時亦表示電子轉移促進之作用可提高對抗細胞膜內外鹽度差異之透壓力環境逆境, 加速染料廢水處理效能。 顯然脫色中間物之累積對染料廢水之促進催化有絕對助益, 加上微生物燃料電池之輔助下處理效果更佳。
\end{abstract}


关键词: 電子梭、紡織染料、微生物產電、微生物燃料電池、染料脫色中間體

\section{1. 引言}

由於偶氮染料被廣泛運用於工業 $(>60 \%)$, 其生物分解 性低，色度於水體中又是顯而易見，因此相關領域之工業 去除此類染料廢水, 已是刻不容緩之重點工作。事實上, 即使是針對環境生態友善性極高之生物處理脫色部分, 研 究指出偶氮染料降解後產生之代謝中間物 (例如: 芳香胺) 亦可能具有相當之生物毒性 [1]，造成對環境生態相當之 衝擊。再者, 地球上 $71 \%$ 面積為海洋所覆蓋的海洋水體, 因此面對如此廣大浩瀚的海洋環境所衍生之各種汗染問 題處理已然是目前需全面謹慎面對解決的課題。事實上, 在技術層次來看, 海水異於一般水體其中鹽度正是第一要 正視之指標特質, 全球海水鹽度各處不一, 約為3.1 $3.8 \%$ 又以地處沙漠周緣之紅海為最高可高達 $4.0 \%$, 北歐波羅的 海由於淡水河流湖泊流入, 則為最低 $1.0 \sim 1.5 \%$, 內陸鹹水 湖則以死海表水鹽度 22.7-27.5\%以上為世界之最; 事實上, 眾多工業 (例如: 石油、食品加工、皮革產業) 亦會產生大 量之高鹽廢水(約佔世界廢水總量5\%;) [2，3]因此高鹽環 境汗染處理乃是全球必須面對之共同問題。本研究即基於 此來考慮在高鹽濃度廢水下, 評估同時進行染料廢水生物 處理之可行性。先前研究即發現在蘭陽平原出海口之狀圍 穊得耐鹽菌, 可同時具有生物脫色及產電之特性。因此本 研究將再進一步量化在高鹽條件下, 以微生物燃料電池來 輔助進行染料脫色之工程優化評估。若此研究為可行, 類 似之邏輯亦可擴大運用於各種汗染物相關之生物復育上。 就微生物生理而言, 一般為生物細胞在面對高鹽環境下, 會因造成之滲透壓差, 而產生脫水現象 [4]。因此如何維 持胞內外滲透壓平衡, 對微生物之存活及生理活性相當重 要。自然界至少存在著嗜鹽（halophilic）及耐鹽 (halotolerant) 兩種耐鹽類型細菌, 近幾年更發現耐鹽菌 (例如：Shewanella aquimarina) [5]可在含高鹽濃度 (7\% 鹽濃度) 之情況下, 進行偶氮染料脱色, 而且由於其耐受 逆境特性, 一般可存活更久, 更可分泌多種酶(例如: 漆酶 (laccase)、NADH-DICP)。有些研究亦顯示可透過共代謝 之手段達到降解偶氮染料 (例如: 偶氮還原酶 (azoreductases) [6]) 來進行染料脫色, 以降低其染料毒 性對其影響, 以達到自我保護之目的, 而偶氮染料降解後 所衍生之芳香胺中間物, 再經由氧化酶 (oxidative enzymes) 以及一系列降解後, 成為幾乎無毒 性之低分子 量之化合物 [7]。事實上, 耐鹽菌由於有阻抗胞內外鹽度 差異之特性, 因此形成許多特殊生物功能, 因此節選耐鹽 功能菌相中極可能節選出於高鹽廢水, 中, 亦具有優異染 料處理之菌株。新近台大團隊即自台南七股鹽山成功篩選 出具貧㾑土壤, 仍可保水生長之本土皮膚醫美面膜菌株 Virgibacillus chiguensis, Marinobacter szutsaonensis $[8,9]$ 。事實上, 含鹽環境下進行染料生物 處理確實是證實具有可行性, Asad et al[10]即指出在染 料廢水中分離純化出三株具有耐鹽能力之菌株 $H$. aquamarina, H. meridiana, 以及 H. salina此三株極度
耐鹽菌, 經過其嚴苛之穊選條件 (20\%鹽濃度, 並且以市售 之七種偶氮染料做為節選染料 (Remazol Black B, Maxilon Blue, Sulphonyl Scarlet BNLE, Sulphonyl Blue TLE, Sulphonyl Green BLE, Remazol Black N, 以及 Entrazol Blue), 最高使用至 $5000 \mathrm{mg} \mathrm{L}^{-1}$ ), 在較高鹽濃度 (1-15\% 鹽濃度皆可進行脫色, 但超過 $10 \%$ 鹽濃度後 Halomonas meridiana, Halomonas salina即開始產生抑 制）下進行染料脫色, Guo et al.（2008）[11]亦提出使用 Halomonas sp. 菌探討降解Reactive Brilliant Red K-2BP 之最佳降解條件, 最適化條件為 $30^{\circ} \mathrm{C}$, 且鹽濃度在 $10-15 \%$ 間可具最佳脫色濃度; Dafale等人 (2008) [12]亦提出以 Pseudomonas aeruginosa及Bacillus circulans混合八種 染料(Reactive Black 5, Reactive Red 11, Reactive Red 141, Reactive Orange 16, Reactive Violet 13, Acid Yellow 36, Acid Orange 7 and Direct Green 6) 在高鹽 濃度條件下處理, 更證實在高鹽濃度環境下, 雖然微生物 生理活性可能被顯著抑制, 但仍具有脫色可行性, 原因在 於提出之菌株最適化生長條件約在 10-15\%鹽濃度, 而顯著 抑制生長之鹽濃度為 $25 \%$ 。本研究則針對此點來探討利用 微生物燃料電池為手段耐鹽脫色菌株之鹽度耐受操作上 限條件及於含鹽條件下脫色之最適化策略, 結論出在高鹽 條件下脫色之可行性策略。再者, 由於其菌株及染料脫色 之限制條件, 亦比一般脫色狀態嚴苛, 雖然菌株可耐受頗 高之鹽度 (10-15\%), 但並非是適合處理染料脫色之最佳鹽 度條件。本研究除了將規範有效量化抑制作用的作法外, 更將估算出一最佳操作條件與策略, 以利於最佳化評估分 析, 運用於實際系統。

就實務而言, 台灣土地面積占全球 $0.025 \%$ 雖然能源、 材料資源極為有限, 但卻占有高達全球 $2.5 \%$ 之生物多樣性, 而且四面環海之豐富海洋資源卻更孕育出高達全世界 $10 \%$ 之生物多樣性。本研究所使用之Shewanella sp. 菌株即自 海洋深層水飼養之象牙鳳螺 (Babylona areolata) 腔腸菌 中節選所得, 希瓦氏菌為目前國際公認之產電菌 (例如: Shewanella putrefaciens, Shewanella oneidensis) [13] [14]) 在世界上廣泛討論及使用, 近年來台灣海洋大 學劉秀美教授團隊更發現Shewanella decolorationis其 產電效能更較國際常使用之Shewanella putrefaciens菌 種佳, 更可分解非偶氮染料之孔雀石綠 (Malachite green)、甲基紫B (Methyl violet B)、結晶紫 (Crystal violet) 多種功能實為一大突破 [15]; 而Meng等人亦指出 在約等於海水鹽度時 (3\%左右), 並不會對希瓦氏菌之脫色 效率產生抑制, 根據文獻亦指出以希瓦氏菌作為種菌, 並 以MFC為手段可有效進行同時脱色產電之研究 [16, 17], 成果更肯定使用希瓦氏菌來作為染料廢棄物處理, 並同時 產電之可行性, 並由於其篩選原生環境之特性, 使其具有 一定之鹽濃度耐受負荷能力。先前研究 [18]更指出, 在篩 選菌株時, 投入較高鹽度來作為限制條件以為篩選, 更可 有效提高節選出高鹽度耐受性之菌株 (Staphylococcus gallinarum, Exiguobacterium indicum), 而且在1\%鹽濃 
度下進行染料脫色 (Reactive Black 5), 可在兩天內脫色 率達到 $75 \%$ 及 $83 \%$ 左右, 然而亦指出其鹽耐受性及脫色效能 兩者並無直接關連, 其脫色之效能主要可能還是只在於菌 種特殊之差異上。

先前研究 [19]指出偶氮染料脫色降解出後, 可能產生 具有促進脫色效能之代謝中間物, Hsueh 等人亦指出活性 綠色19號(Reactive Green 19)染料之脫色中間產物, 可 能由於含芳香胺及有機硫化物, 而具有電子梭 $(\mathrm{ESS})$ 之效 果, 於後續研究中, 亦以類似脫色所衍生降解之模式芳香 胺中間物進行結構上比較測試, 例如:2-氨基苯酚 (2-Aminopheno1) [20,21]、鄰苯二酚、鄰苯二胺 (Pyrocatechol、Benzene-1, 2-diamine) [22]、1-胺基, 2-

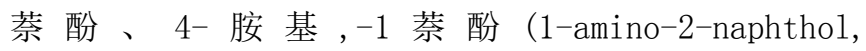
4-amino-1-naphthol[23]) ( 具 有 $-0 \mathrm{H},-\mathrm{NH}_{2}$, $-\mathrm{N}\left(\mathrm{CH}_{3}\right) \mathrm{H},-\mathrm{N}\left(\mathrm{CH}_{3}\right)_{2}$, malachite green (MG), azure A and azure C) [24], 更證實皆可作為電子梭 (ESs) 來使用, 上 述研究一再地闡明染料脫色後之代謝中間體, 極可能作為 電子梭 $(\mathrm{ESS})$ 之可行性; 在以 MFC為處理汗染物之手段條件 下, 進行同時脫色產電, 即使生物脫色及產電為競爭關係 [25]下，仍可證明以MFC為手段確實能增進單位時間內電 子總流量之產生 [17]; 文獻 [3] 指出當增加 NaCl濃度時, 可增進離子強度, 達到降低內阻之目的, 並且提昇電導度 之功用, 並進一步提高產電效能。相反地, 前述提及在過 高鹽度下, 將會造成微生物生長抑制作用, 因此在微生物 燃料電池做手段進行同時脫色及產電, 期望能以提升鹽濃 度之方式來提高離子及電子轉移之效率, 以提昇產電。因 此在以MFC為手段下, 對鹽濃度的最佳化及脫色中間物累 積添加量探討是相當必要的, 本研究首度規範定義之量化 值算公式下，量化各種代謝中間物為電子核下，於含鹽染 料人造廢水中之脫色促進亦或是抑制效果, 藉此來歸納出 含鹽染料廢水處理之最優化條件。

\section{2. 材料與方法}

\section{1. 菌株篩選條件}

首先取定花蓮外海之太平洋海洋深層水 (約 $3.5 \%$ 鹽濃 度) 為培食水源以及海洋水產生物象牙鳳螺 (Babylonia areolata) 為培養生物反應器, 取其腔腸道代謝分解食物 後之排遺來進行海洋功能性菌株之篩選。(註: 花蓮離海岸 線5 km處, 於海面下 $660 \mathrm{~m}$ 所取得之深層海水, 因此富含各 種礦物離子之積累, 造成至少可含有 ${ }^{\sim} 70$ 種稀有元素之獨 特優越條件, 是以選取用來做為以培養耐鹽及離子之菌株 節選基底介質, 以用來培養本土海洋水產生物鳳螺。所有 腔腸菌相富集培養, 再優勢篩選培養篩選功能菌株, 均先 以0.2S Luria-Bertani (SLB) (Tryptone: $10 \mathrm{~g} / \mathrm{L}$ 、Yeast extract: $5 \mathrm{~g} / \mathrm{L} 、 \mathrm{NaCl}$ : $30 \mathrm{~g} / \mathrm{L}$ ) 以及海洋培飬基Marine Broth 2216 培養基 (引自 Atlas, Ronald M, Microbiological Media, p811), 作為培養基質, 以進行 脫色菌株之篩選。因於高鹽濃度下, 能有效降低電池內阻, 並促進電子轉移之功效, 再結合染料脫色作為誘導電子轉 移之篩選條件，因此選定RBu160、RBu198、RR141、D039、 RY84、RBk5此六種模式染料 [26], 分別添加50 mg L ${ }^{-1}$ 進行,
並於二次馴養後, 取定以RBu160, RBu198作為馴養之混菌 來進行分離純化, 目標在於篩選出具耐鹽性、高染料處理、 高產電之特殊功能性菌株。

\section{2. 中間物添加及微生物培養條件}

首先選定䒺酚 (Naphthol) 模式染料反應紅 141 號 (RR141)、反應紅198 (RB198)、酸性橙20號 (Acid Orange 20, OI) (購自台灣永光化學、台灣友和公司) 以Shewanella sp. WLP72進行脫色, 當脫色殘留 $<10 \%$ 後之脫色代謝物, 取定 利用以用來測試是否具有刺激產電及脫色之能力。本研究 所用之希瓦氏菌WLP72乃是由象牙鳳螺之腔腸排遺菌相篩 選出優是純化所得之本土海洋脫色菌株, 藉由從平板上勾 選出之純菌菌落作為菌源, 在 $125 \mathrm{rpm}$ 下經過兩次換瓶培養 (一次 $12 \mathrm{hr}$ ), 再由搖瓶內取 $1 \%$ 之菌液加入新鮮培養基中, 並加入 $2000 \mathrm{mg} \mathrm{L}^{-1}$ 上述三種模式染料, 以製成濃縮脫色中 間物, 經過六小時好氧培食後, 進行靜置脫色, 完成後, 將培養液高速離心後, 留上層澄清液保存, 以利於後續相 關研究追路應用分析。

\section{3. 單槽式微生物燃料電池模組}

本研究使用空氣陰極單槽式微生物燃料電池 (single-chamber MFCs, SC-MFCs), 來作為微生物產電及 脫色之模式電池。取定聚甲基烯酸甲酯 (Polymethylmethacrylate, PMMA) 材質槽體組裝成單槽 式微生物燃料電池 (其基本電池結構詳見) [19]。首先取定 長 $95 \mathrm{~mm}$, 厚 $3 \mathrm{~mm}$, 內徑 $54 \mathrm{~mm}$ 圓管一支, 一端作為陽 極閉口端, 另一開端作為空氣陰極開口, 以此段槽體做為 微生物處理廢水之陽極反應槽。圓管距兩端邊緣 $10 \mathrm{~mm}$ 處對稱平面上分別鑽出直徑 $6 \mathrm{~mm}$ 之孔洞, 並接合長 30 $\mathrm{mm}$, 內徑 $3 \mathrm{~mm}$ 的玻璃管以作連續操作評估, 邊緣再以矽 利康（silicone）固定玻璃管, 並在陽極槽正中央鑽出直 徑 $11 \mathrm{~mm}$ 的孔洞, 以作為後續可置參考電極與輔助電極 之位置, 利於電化學分析儀對電池測量。在殖種微生物前, 先以 $3 \%$ 之雙氧水 $\left(\mathrm{H}_{2} \mathrm{O}_{2}\right)$ 對電池模型進行消毒 24 小時後, 再 於無菌條件, 排出雙氧水後, 以高溫殺菌超純水 (sterile ultrapure water), 反覆沖洗微生物燃料電池模組, 再以 超純水加滿靜置24小時, 以全流動快速洗淨去除以防止可 能殘留之雙氧水, 放置24小時後, 再除去清洗之超純水, 以利於進行培養微生物及功能性評估。在菌株添加時分別 添入電池 $\mathrm{A}\left(20 \mathrm{~g} \mathrm{~L}^{-1} \mathrm{NaCl}\right)$ 及電池B $\left(30 \mathrm{~g} \mathrm{~L}^{-1} \mathrm{NaCl}\right)$ 比較 以探討其鹽濃度對於MFC之影響。

\section{4. 染料脫色評估}

本研究選定偶氮染料反應藍 160 號為模式染料 $\left(\lambda_{\max }=616 \mathrm{~nm}\right)$, 來探討其不同脫色代謝物對其脫色之影 響, 測試中添加濃度為 $200 \mathrm{mg} \mathrm{L}^{-1}$ 以利於與過去研究進 行比較分析, 在以 Shewane1la sp. WLP72 培飬下, 於 $125 \mathrm{rpm}$ 下經過兩次培養 (一次 $12 \mathrm{hr}$ ), 再由搖瓶內取 $1 \%$ 之菌液加入新鮮培養基, 並同時加入預先配製之脫色中 間物濃縮液以及模式染料, 進行脫色實驗。研究中比生 長速率 $(\mathrm{SGR})$ 以及比脫色速率 $(\mathrm{SDR})$ 定義之公式乃是經 
由微生物生長及染料時間曲線來估算 [27]如下：

$$
\begin{gathered}
S G R=\frac{d \ln X}{d t} \cong\left(\frac{1}{X}\right)\left(\frac{\Delta X}{\Delta t}\right) \\
S D R=-\left(\frac{1}{X}\right) \frac{d[D y e]}{d t} \cong-\left(\frac{1}{X}\right) \frac{\Delta[D y e]}{\Delta t}
\end{gathered}
$$

其中X, [Dye]分別代表菌體及染料濃度。

\section{5. $\mathrm{MFC}$ 產電及脫色}

使用經過長期馴養, (約360天) 達到穩定之MFC, 在以 兩天為添加基質之週期條件下, 並在每次添加基質時加入 $450 \mathrm{mg} \mathrm{L}^{-1}$ 反應性藍色 160 號 (RBu160) 染料以及預先配製 之模式染料脫色中間物 (分別為RR141-DM, RR198-DM, Orange I-DM), 以進行分析評估, MFC之電壓外電阻為 $1 \mathrm{k}$ $\Omega$ 條件下, 進行連續監測 [19], 染料脫色時間曲線, 則以 分光光度計 (HACH DR 3900) 取電池內菌液經12500 rpm離 心後取上清液, 以最大吸收波長 $616 \mathrm{~nm}$ 進行監測。

\section{3. 結果與討論}

\section{1. 耐鹽菌株笁選}

圖1鹽度電導度分析指出, 當 $\mathrm{NaCl}$ 鹽度自 $5 \mathrm{~g} \mathrm{~L}^{-1}$ 增高, 電阻逐漸有顯著下降趨勢, 當鹽度增加, 電阻持續下降, 其電導度亦持續增加。事實上, 微生物燃料電池之內阻與 其產電能力有極大之相關性, 若內阻越大, 電子及離子轉 移效率自然降低。但是鹽度過高, 對菌株則會形成胞內外 滲透壓力, 而抑制其生長活性。因此本研究選用針對鹽度 之培飬基及耐鹽之菌株進行研究評估, 由增強電子轉移, 並考慮耐鹽菌株之生存及產電活性評估, 以利於有效降低 微生物燃料電池之內阻, 提高脫色及產電效能。因此選定 富含多種離子之海洋深層水來篩選海洋功能菌種 (株) 以 作為探討電子轉移相關之生物技術可行性應用。本研究即 以此目標來評估應用於高鹽度條件下之脫色生物處理之 最佳化操作條件評估。因此將原先微生物篩選初期所選用 兩種培養基, 分別為Marine 2216海洋生物培養基, 以及 將LB內含鹽度調整為 $30 \mathrm{~g} \mathrm{~L}^{-1}$ 來進行菌株篩選, 先前研究 Chen et al. (2013) [22] 指出生物脫色及產電為競爭作用, 由於其產電及脫色皆涉及電子轉移, 故在篩選時, 以加入 偶氮染料 (分別為RBu160，RBu198，RR141，RBk5，RY84, D039) 為限制條件, 來進行優勢純化篩選。在篩選過程中, 使用較高鹽度培養基以及特定染料限制條件雙重限制條 件, 其目的在於以其染料脫色之機制與產電相似之原理來 刺激微生物放出電子, 並同時先行馴養微生物對 $\mathrm{NaCl}$ 之耐 受性, 由於前言文獻提及之生物耐受性問題, 為避免在投 入高鹽度MFC後, 因鹽度造成之抑制效果, 因此以其為限 制條件之一先進行馴化; 在兩次染料馴化之過程中, 第一 次先將鳳螺腔腸混菌投入分別裝有前述六種染料之兩種 試管培養基 (Marine 2216, $0.2 \times \mathrm{xB}\left(30 \mathrm{~g} \mathrm{~L}^{-1} \mathrm{NaCl}\right)$ ), 並
選定最快脫色完成之試管(皆為兩種試管培飬基中之 RBu160, RBu198, 此兩種染料之試管脫色最佳), 再進行第 二次馴化, 時再將第一次最快脫色試管, 再次加入同樣上 述六種染料試管中, 同樣選取最快脫色之試管 (RBu160, RBu198), 再分別以四分畫菌純化分離方式塗抹於Marine 2216 Agar以及LB Agar (30 g L $\left.{ }^{-1} \mathrm{NaCl}\right)$ 經三次塗抹後最後 取定特殊性質之菌株(在低溫條件下呈現橘紅色之菌株)。 再分離菌株後, 經細胞破碎提取其蛋白質, 再以SDS-PAGE 進行蛋白質表達分布比對, 依此選出一株優異脫色菌株, 後經16S rRNA基因定序以基因庫中親緣樹序列鑑定與 Shewanella haliotis 有 $99.7 \%$ 以上之相似度 (圖2), 此為 一東台灣本土海洋菌屬菌株, 希瓦氏菌菌屬目前為世界公 認以奈米導線進行電子轉移之產電菌種, 因此用於高鹽條 件下, 進行脫色以及產電之相關探討及研究。

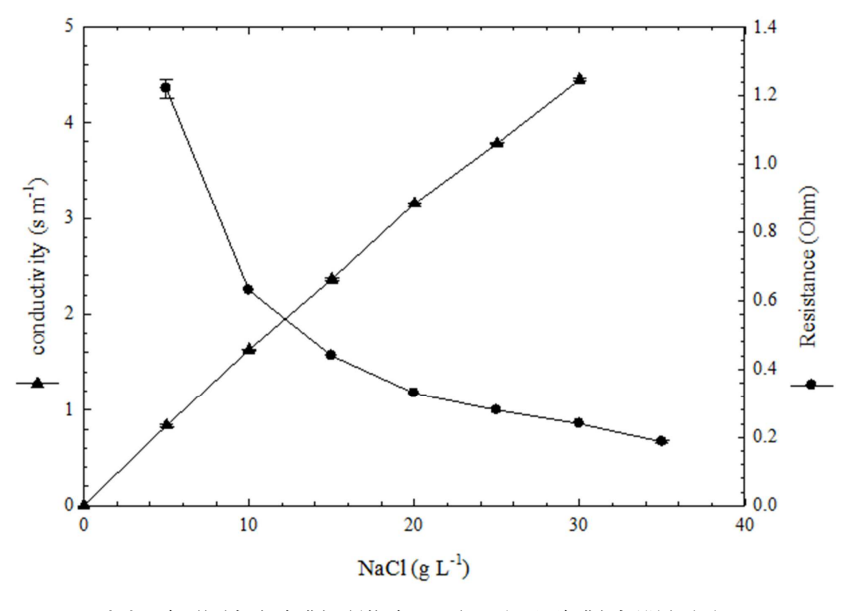

圖1 氯化鈉鹽度對電導度及電阻之影響對應關係圖。

\section{2. 循環伏安分析}

首先取定RBu171，RR198，RR141，RBk5，Orange I 五種模式染料之脫色中間物, 分別進行循環伏安圖譜掃描, 其中脫色中間物具有較顯著之氧化還原峰值 (圖 3，4) 可 分別計算出電子轉移數目 $\mathrm{n}^{\mathrm{c}}$ 及電子梭強度大小 $[24]$, 例 如: Orange I 其氧化峰電位為 $-0.2021 \mathrm{~V}$, 還原峰電位為 $0.026 \mathrm{~V}, \mathrm{E} \mathrm{o}_{0}$ 值為 $-0.088 \mathrm{~V}, \mathrm{n}$ 值為 0.25 , 次之RR 141 , 其氧 化還原峰電位分別為 $-0.1769 \mathrm{~V},-0.0129 \mathrm{~V}, \mathrm{E}^{\prime}$ 。值為 $-0.0949 \mathrm{~V}, \mathrm{n}^{\mathrm{c}}$ 值為 0.35 , 最佳的是RR198, 其氧化還原峰 電位分別為 $-0.1079 \mathrm{~V}, 0.05014 \mathrm{~V}, \mathrm{E}$ 。值為 $-0.029 \mathrm{~V}, \mathrm{nc}$ 值 為0.36, 而RBu171, RBk5則無明顯峰值顯現。可能原因是 在此介質條件下, 其電子轉移特性, 並不能顯著地顯現出 來。由 $\mathrm{E}^{\prime}$ 。值排序可知, 各種脫色代謝物 $\mathrm{E}^{\prime}$ 。值皆比 $\mathrm{NADH}$ 氧 化還原電位 $-0.32 \mathrm{~V}$ 為大, 因此可自 $\mathrm{NADH}$ 來獲取電子進行轉 移。再者, 由三種代謝物 E'。值可知, RR141 > OI > RR198 電子轉移強度之大小次序來排列。由於 $\mathrm{n}^{\mathrm{c}}$ 值 $<1$, 代表轉 移較緩和。CV圖譜中顯著之氧化還原峰表現可用來作為篩 選出具電子梭 (ESs) 之可能脫色中間物。 


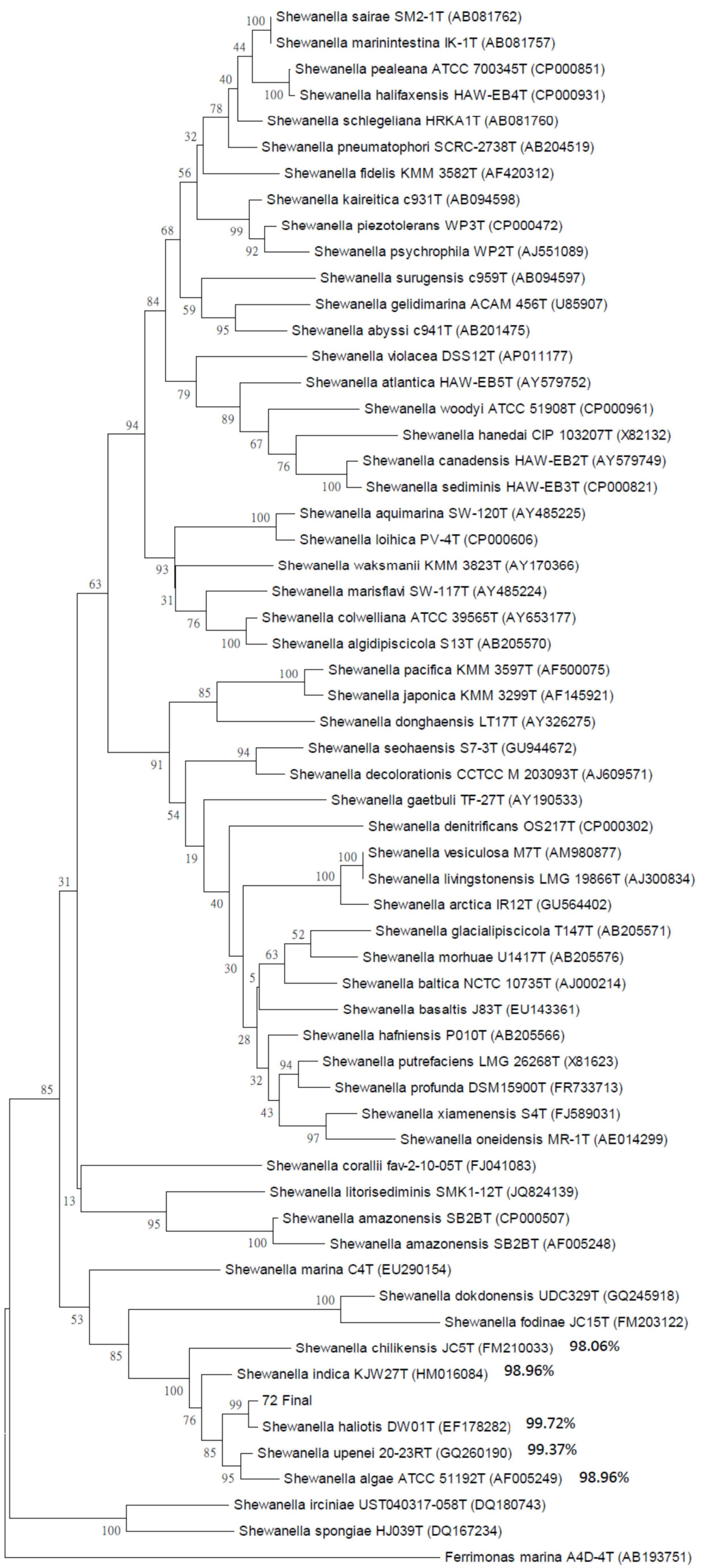

圖2 Shewanella sp. WLP72 經16S rRNA 基因序列親源鑑定樹狀圖, 從基因庫GenBank 比對與Shewanella haliotis DW01T 有99. 72\%之相似蛋白質 表現。 


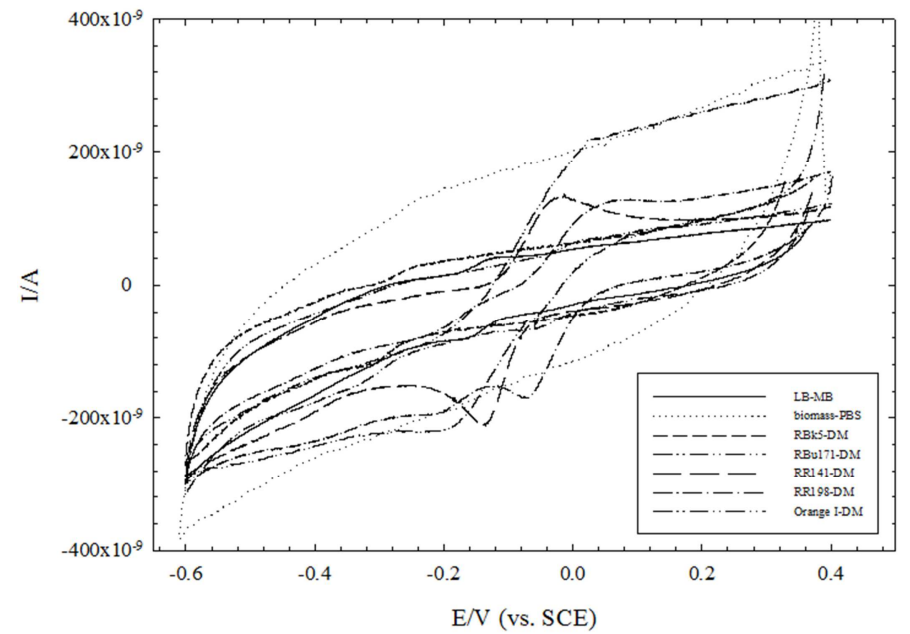

圖3 五種偶氮染料脫色代謝物 RBk5-DM，RBu171-DM，RR141-DM，RR198 -DM，Orange I-DM，LB基質消耗完之空白組以及單純WLP72菌株+PBS緩衝溶 液之循環伏安圖譜對應圖（掃描速率 $1 \mathrm{mV} \mathrm{s}^{-1}$ )。

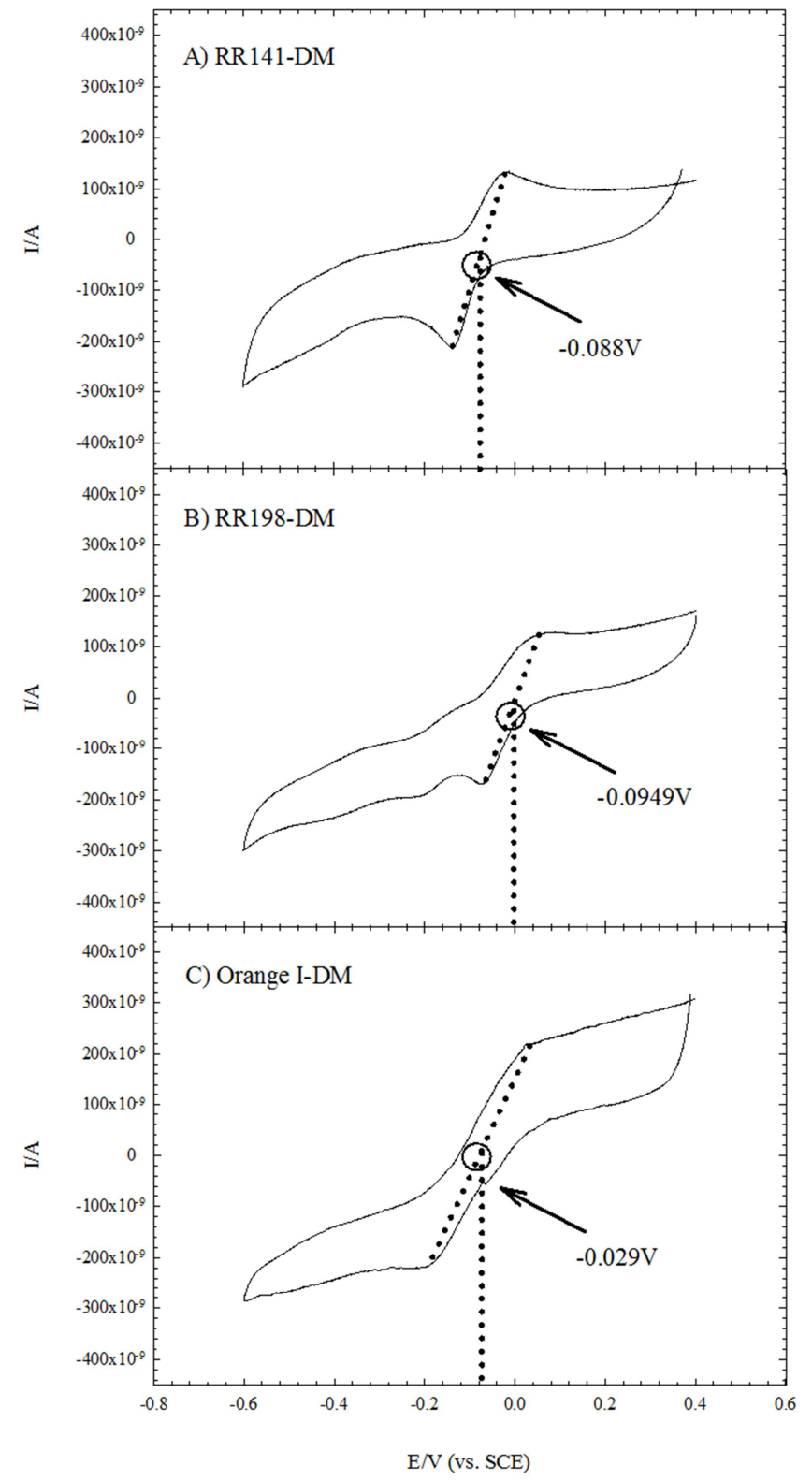

圖4 三種染料代謝物RR141-DM（A)，RR198-DM（B)，Orange I-DM (C) 之氧化還原過程示意圖（scan rate $=1 \mathrm{mVs}^{-1}$ )。 


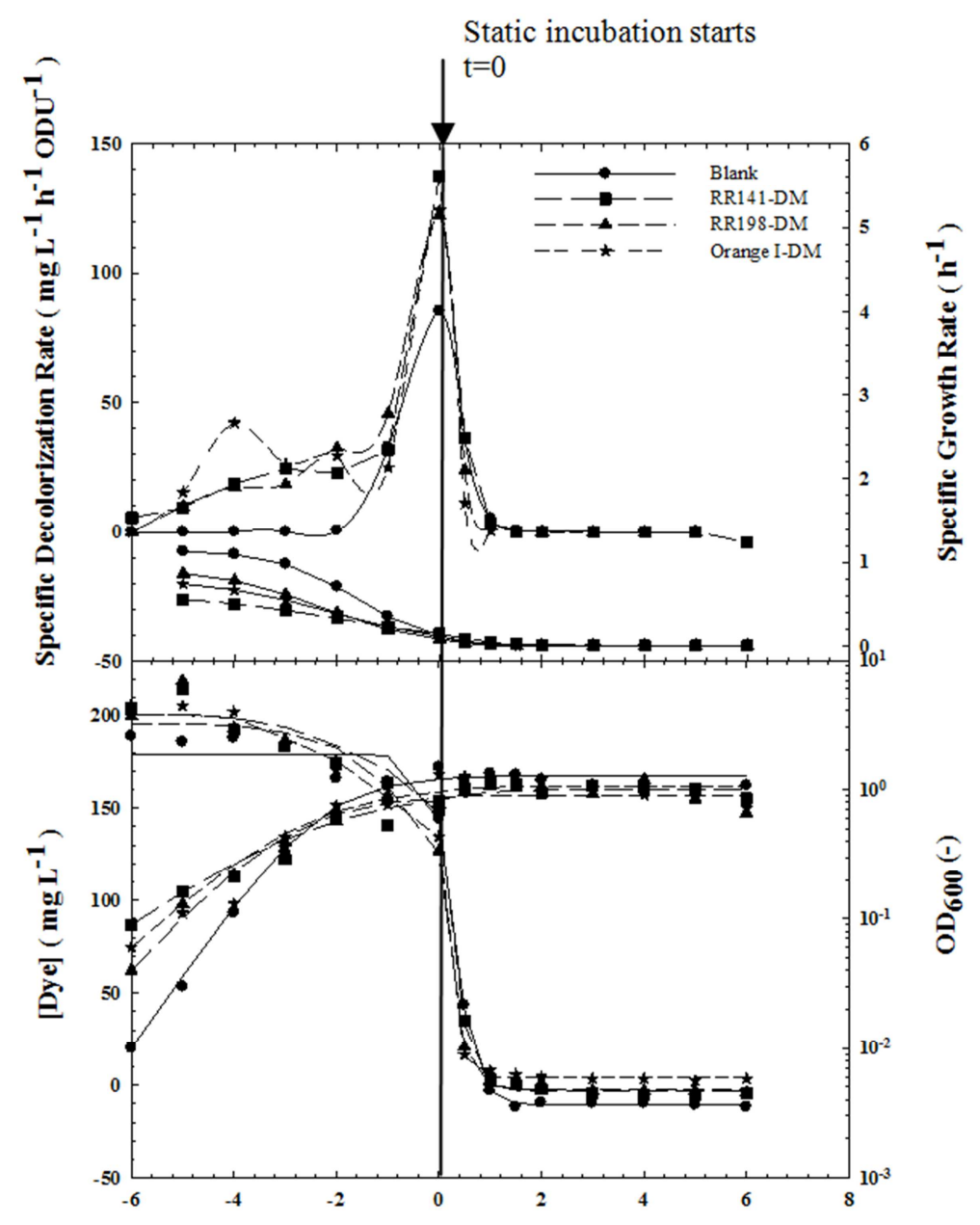

圖5 WLP72對起始濃度約 $200 \mathrm{mg} \mathrm{L}$ 染料RBu160下，添加脫色中間物RR141-DM，RR198-DM，Orange I-DM下WLP72菌株之微生物生長及脱色時間曲線比 較圖。

\section{3. 脫色中間物刺激脫色}

先前研究 [25]指出芸酚類染料之脫色中間產物有作 為氧化還原電中介體之能力，可用來刺激脫色，因此可同 理推論此類染料脫色中間物亦可能具有電子梭 (ESs) 之能 力, 因此本研究RR141、RR198、0I脫色中間物進行搖瓶脫 色試驗, 來量化評估其脫色代謝物促進效果 (圖5), 而其 結果顯示最佳SDR之脫色代謝物分別為RR141 (137.55 mg $\left.\mathrm{L}^{-1} \mathrm{~h}^{-1} O \mathrm{DU}^{-1}\right)$, 次之為 $0 \mathrm{I}\left(124.2 \mathrm{mg} \mathrm{\textrm {L } ^ { - 1 }} \mathrm{h}^{-1} O \mathrm{DU}^{-1}\right)$, 以及 RR198 (122. $\left.3 \mathrm{mg} \mathrm{L}^{-1} \mathrm{~h}^{-1} 0 \mathrm{DU}^{-1}\right)$, 此大小排列次序與2.2節之 $E^{\prime} 0$ 排列次序兩相平行, 更證實脫色是與電子轉移密不可 分。在量測循環伏安圖譜時, 所決定出來之E' 0 值極可能 可評比出其脫色能力之優劣, 是一種更簡易及客觀之評價 指標。未添加中間物之空白值 (Blank) (85.44 mg L ${ }^{-1}$ $\mathrm{h}^{-1} O D U^{-1}$ ) 則最差, 代表上述脫色代謝物確實能有效促進染 料脫色, 提昇約 $43 \%-61 \%$ 。

\section{4. 同時產電及脫色 (SBG\&DD), 單純產電 (BG) 及脫色 (DD alone) 比較分析}

本研究使用自行提出之量化評估方法 [17]來討論估 算電子轉移之效率, 首先假設在MFC決源於環境之條件下, 在外電阻 $1 \mathrm{k} \Omega$ 下, 進行同時脫色及產電測試; 另取外電阻
為 $\mathrm{R}_{\mathrm{ex}}=\infty ;($ 即斷路)下, 進行脫色試驗 (即DD alone), 另取無染料添加下, 在 $R_{e x}=1 \mathrm{k} \Omega$ 下進行產電 (即BG alone) 分析, 並假設DD alone 及 BD alone系統中電子轉移 “數 目相等” 之條件下, 估算單位染料脫色所消耗之電子轉 移數目, 對應 “當量” 關係, 再以此條件來換算同時產電 及脫色操作下之電子轉移效率, 以進行比較。依據 $[3]$ 在 微生物燃料電池中提高鹽度下, 產電情況確實有極大幅度 改善, 其指出在 $0 \mathrm{~g}$ 以及 $5 \mathrm{~g} \mathrm{~L}^{-1} \mathrm{NaCl}$ 之情況下, 產電皆較 LB之 $10 \mathrm{~g} \mathrm{~L}^{-1} \mathrm{NaCl}$ 為低, 持續增加至 $20 \mathrm{~g} \mathrm{~L}^{-1} \mathrm{NaCl}$, 可有 最高之功率密度, 但增加至 $40 \mathrm{~g} \mathrm{~L}^{-1} \mathrm{NaCl}$, 則產生嚴重抑 制作用文獻 [19] 指出以耐鹽條件穊選出之菌株 (Staphylococcus gall inarum) 其 $\mathrm{EC}_{70}$ 值為 $130 \mathrm{~g} \mathrm{~L}^{-1}$ ，但並 非耐鹽即代表對生物產電脫色有平行之效果, 文獻即指出 [5] Shewanella aquimarina 在5\%鹽度下, 保持約 $5 \mathrm{hr}$ 完成 脫色 $90 \%$ 以上，但在8\%鹽濃度下則發生脫色遲緩現象， $10 \%$ 則無法在 $12 \mathrm{hr}$ 內完成脫色。因此本研究深入探討在具鹽濃 度壓力下之同時脫色產電處理最適化條件。又例如: 文獻 [3] 指出之 $20 \mathrm{~g} \mathrm{~L}^{-1}$ 鹽濃度下會有最佳之功率密度並與一般 海水鹽度之鹽濃度 $30 \mathrm{~g} \mathrm{~L}^{-1}$ 以及一般LB培飬基 $10 \mathrm{~g} \mathrm{~L}^{-1}$ 濃 度互相比較評估, 以已知之最佳產電鹽濃度來測試其產電 及脫色之關係, 進而探討出鹽濃度對其之相互影響。 Lefebvre et al. (2006) [28]亦指出若在處理含有高鹽濃 
度汗泥條件下, 對於微生物處理廢棄物狀態產生相當之負 面影響（例如：因抑制生物生長造成脫色延遲甚至無法脫 色)；Chen et al. (2013) [22]更論述到生物產電及生物 脫色皆涉及電子轉移, 因此形成競爭關係。因此在此首先 探討在較高鹽度下，以增強產電或誘導電子轉移作為先決 條件, 對於微生物燃料電池內部進行脫色及產電之影響評 估，並依Han et al. （2015) 及Chen et al. (2015) [17, 24] 提出之計算公式，針對其SBG\&DD，單純BG及單純DD 來與 以工程評價分析。對於在高鹽條件下，微生物燃料電池作 為操作手段之產電以及脫色之定量結果 (表1), 可得出此 項大小排列 (註： $\phi=1$ 可假設為一般 $10 \mathrm{~g} \mathrm{~L}^{-1} \mathrm{NaCl}$ 鹽度條 件下基準值)

(1) WLP72-10 g L L $^{-1} \mathrm{NaCl}$ ( $\phi$ 值大小次序)

Blank (1.58) > RR198-DM (1.75) > RR141-DM(1.23) > Orange I-DM (1. 15)

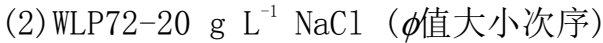

$\operatorname{RR} 198-\mathrm{DM}(1.47)>$ Orange $\operatorname{I-DM}(1.34)$

RR141-DM (1.04) > Blank (0.61)

(3) WLP72-30 g L ${ }^{-1} \mathrm{NaCl}$ ( $\phi$ 值大小次序)

RR141-DM (2.54) > 0range I-DM (1.47)

RR198-DM (1.07) > Blank (0.62)

依據上述結果，在添加脫色中間物結合MFC為操作模 式下，可有效刺激並提升微生物燃料電池之電子總移轉量 (約1.04至2.54倍>1.0), 進而達到超越單純產電及脫色之
電子釋出量, 然而在未添加脫色中間物之對照空白條件下, 其電子轉移數量亦僅有單純脫色或產電效能之六成左右, 而對照 $10 \mathrm{~g} \mathrm{~L}^{-1}$ 鹽濃度下可以看出其電子總轉移量為 Blank (1.58) > RR198-DM(1.75) > RR141-DM(1.23) > Orange I-DM (1.15), 除證明在以MFC為操作手段下能有效 提升電子總轉移量外 (約1.15至1.75倍 > 1.0), 也證實若 在一般生理食鹽水鹽濃度 (約 $1 \% \mathrm{NaCl}$ ) 下若無鹽度抑制微 生物情形發生其總效能皆可有效提升。因此此點更可直接 量化出鹽度對生物活性之壓抑效果, 根據Lefebvre et al. (2012) [3] 指出在 $5 \mathrm{~g} \mathrm{~L}^{-1}, 20 \mathrm{~g} \mathrm{~L}^{-1}, 40 \mathrm{~g} \mathrm{~L}^{-1}$ 鹽濃度下, 其 庫倫效率分別為 $58 \pm 3 \%, 28 \pm 1 \%$ and $22 \pm 3 \%$, 此 結果更指出較高之鹽度對於微生物生理狀態有負面影響, 本研究則指出加入脫色代謝物後, 可有效抵抗鹽度大為提 高其電子轉移效率來進行高效率脫色。因此推論在以MFC 為手段下, 能更有效促進脫色, 若在 (染料添加及高鹽濃 度產電強化) 雙重限制條件下, 若超出微生物對於其之耐 受極限仍會產生抑制作用。例如：Shewanella decolorationis [29] 即在1-3\%鹽濃度時生長之倍率提昇 了 $17.6-27.6 \%$, 而在鹽濃度增加至4-5\%時, 觀察到抑制效 果, 在6-7\%時則生長完全抑制, 而Shewanella oneidensis 則在 $0.6-2.3 \%$ 鹽濃度時, 能正常生長 $\left(0 D_{600}\right.$ 值約為 $1.0-1.1$ 之間)，但提昇至 $2.9 \%$ 時則生長大幅降低 $\left(0 \mathrm{D}_{600}\right.$ 值僅約 0.2 左右) [30], 由此得知上述菌株可能在 $3 \%$ 鹽濃度即出現生 長抑制情形。

表1 同時脱色產電, 單純產電以及單純脫色性能比較示意表。

WLP72-10

\begin{tabular}{|c|c|c|c|c|c|c|c|c|c|}
\hline \multirow{2}{*}{$\begin{array}{l}\text { Metabolite } \\
\text { species }\end{array}$} & \multicolumn{3}{|l|}{ SBG\&DD } & \multicolumn{2}{|c|}{ BG alone } & \multirow{2}{*}{$\begin{array}{l}\text { DD alone } \\
I D R_{\mathrm{d}} \\
\end{array}$} & \multirow{2}{*}{$a=\frac{I D R_{d}}{k_{e} V_{0 e}}$} & \multirow{2}{*}{$\eta=\left(k V_{0}\right) a+I D R$} & \multirow{2}{*}{$\phi=\frac{\eta}{I D R_{\mathrm{d}}}$} \\
\hline & IDR & $k V_{0}$ & $k$ & $k_{\mathrm{e}} V_{0 \mathrm{e}}$ & $k_{\mathrm{e}}$ & & & & \\
\hline Blank & 1.026 & 46.38 & 0.449 & 73.87 & 0.521 & 1. 081 & 0.0146 & 1.709 & 1.58 \\
\hline RR141-DM & 1. 053 & 49.62 & 0.447 & 147.83 & 0.981 & 1. 173 & 0.00794 & 1. 447 & 1.23 \\
\hline RR198-DM & 1. 424 & 46. 92 & 0.384 & 57.7 & 0.495 & 1. 516 & 0.0263 & 2. 658 & 1.75 \\
\hline Orange I-DM & 1. 127 & 46.39 & 0.541 & 120.7 & 1. 584 & 1. 470 & 0.0122 & 1. 693 & 1.15 \\
\hline
\end{tabular}

WLP72-20

\begin{tabular}{|c|c|c|c|c|c|c|c|c|c|}
\hline \multirow{2}{*}{$\begin{array}{l}\text { Metabolite } \\
\text { species }\end{array}$} & \multicolumn{3}{|l|}{ SBG\&DD } & \multicolumn{2}{|c|}{ BG alone } & \multirow{2}{*}{$\begin{array}{l}\text { DD alone } \\
I D R_{\mathrm{d}}\end{array}$} & \multirow{2}{*}{$a=\frac{I D R_{d}}{k_{e} V_{0 e}}$} & \multirow{2}{*}{$\eta=\left(k V_{0}\right) a+I D R$} & \multirow{2}{*}{$\phi=\frac{\eta}{I D R_{\mathrm{d}}}$} \\
\hline & IDR & $k V_{0}$ & $k$ & $k_{\mathrm{e}} V_{0 \mathrm{e}}$ & $k_{\mathrm{e}}$ & & & & \\
\hline Blank & 0.417 & 44.62 & 0.388 & 144.4 & 0.751 & 1.389 & 0.00962 & 0.846 & 0.61 \\
\hline RR141-DM & 0.725 & 41.96 & 0.479 & 66.66 & 0.438 & 1. 757 & 0.0263 & 1.829 & 1.04 \\
\hline RR198-DM & 1. 186 & 31.45 & 0.32 & 50.02 & 0.291 & 1. 404 & 0.0281 & 2. 070 & 1. 47 \\
\hline Orange I-DM & 1. 047 & 18.35 & 0.162 & 66.79 & 0.375 & 0.988 & 0.0148 & 1. 319 & 1. 34 \\
\hline
\end{tabular}

WLP72-30

\begin{tabular}{|c|c|c|c|c|c|c|c|c|c|}
\hline \multirow{2}{*}{$\begin{array}{l}\text { Metabolite } \\
\text { species }\end{array}$} & \multicolumn{3}{|c|}{ SBG\&DD } & \multicolumn{2}{|c|}{ BG alone } & \multirow{2}{*}{$\frac{\text { DD alone }}{I D R_{\mathrm{d}}}$} & \multirow{2}{*}{$a=\frac{I D R_{d}}{k_{e} V_{0 e}}$} & \multirow{2}{*}{$\eta=\left(k V_{0}\right) a+I D R$} & \multirow{2}{*}{$\phi=\frac{\eta}{I D R_{\mathrm{d}}}$} \\
\hline & IDR & $k V_{0}$ & $k$ & $k_{\mathrm{e}} V_{0 \mathrm{e}}$ & $k_{\mathrm{e}}$ & & & & \\
\hline Blank & 0.863 & 53.36 & 0.43 & 312.1 & 2.85 & 1.872 & 0.0059 & 1.178 & 0.62 \\
\hline RR141-DM & 1. 434 & 193.5 & 1. 238 & 113. 2 & 0.72 & 1.719 & 0.0152 & 4. 375 & 2.54 \\
\hline RR198-DM & 1. 449 & 37.56 & 0.272 & 135.6 & 0.883 & 1.821 & 0.0134 & 1.952 & 1. 07 \\
\hline Orange I-DM & 1. 359 & 169.2 & 1. 031 & 250.4 & 2. 08 & 1.707 & 0.00681 & 2. 511 & 1. 47 \\
\hline
\end{tabular}

IDR: Initial decolorization rate (umole $\mathrm{L}^{-1} \mathrm{~h}^{-1}$ ) (refer to [20])

$V_{0}$ : Maximal output voltage $(\mathrm{mV})$ (refer to $[20]$ )

$k$ : Decay rate constant $k\left(d^{-1}\right)$ (refer to [20])

a: The ratio of electrons transferred of IDRd to $k_{e} V_{0_{e}} ;{ }^{a=\frac{I D R_{4}}{k \cdot V_{e}}}$ (umole $\mathrm{L}^{-1} \mathrm{~h}^{-1} \mathrm{mV}^{-1} \mathrm{~d}$ )

$\eta$ : Overall equivalent electrons transferred $\eta=I D R+a\left(k V_{0}\right) \quad\left(\right.$ umole $\left.L^{-1} h^{-1}\right)$

$\phi$ : 0verall “stoichiometric" ratio of electron transport $\phi=\eta / I D R_{\mathrm{d}}$ 
但在單純脫色以及單純產電時, 仍然能得到較高的產 電以及脫色結果。依此結果推論, 一般而論之MFC促進作 用在高鹽度下之, 若添加染料脫色代謝物後, 更能有效克 服此鹽度負荷問題, 證實在高鹽度MFC操作下, 添加染料 脫色中間物更可為有效脫色處理策略及方式。

\section{4. 結論}

本研究以新型量化計算方式定義其鹽濃度對於為生 物燃料電池內之實際影響狀態, 並發現在鹽濃度為 $2-3 \%$ 時會使 MFC 在同時進行脫色及產電時整體效能較鹽濃度為 $1 \%$ 時降低 $60 \%$, 然而經過添加染料脫色中間物, 以染料廢 水處理時所產生之中間物, 以其做二次再利用, 即可使得 $\mathrm{MFC}$ 模組在有鹽濃度抑制生物生長之情沉下, 依然擁有促 進脫色及產電之效果, 因此若以處理高鹽度廢水處理, 考 量鹽度所帶來之生物生長抑制情形, 添加染料脫色中間物 極具可行性, 因此後續考量應以鹽濃度以及染料脫色中間 物添加之最適化設計作為工程化應用之目標。

\section{致謝}

感謝烟台大學與宜蘭大學交換學生韓克協助, 以及國 立高雄海洋大學陳文明教授之菌種鑑定及科技部之經費 補助及產學合作計畫經費補助（計畫編號：NSC 102-2221-E-197-016-MY3、104-2622-E-197-006-CC3）。

\section{参考文献}

[1] B. G. Gesche S. Heiss, Eric R. Dabbs, FEMS Microbiology Letters, 99 (1992).

[2] 0. Lefebvre, S. Quentin, M. Torrijos, J. J. Godon, J. P. Delgenes, R. Moletta, Applied microbiology and biotechnology, 75 (2007) 61-69.

[3] 0. Lefebvre, Z. Tan, S. Kharkwal, H. Y. Ng, Bioresource technology, 112 (2012) 336-340.

[4] L. Chun, L. Li-bo, S. Di, C. Jing, L. Ning, Journal of Northeast Agricultural University (English Edition), 19 (2012) 66-74.

[5] X. Meng, G. Liu, J. Zhou, Q. Shiang Fu, G. Wang, Bioresource technology, 114 (2012) 95-101.

[6] K. H. Balapure, K. Jain, S. Chattaraj, N. S. Bhatt, D. Madamwar, Journal of hazardous materials, 279 (2014) 85-95.

[7] R. G. Saratale, G. D. Saratale, J. S. Chang, S. P. Govindwar, Journal of the Taiwan Institute of Chemical Engineers, 42 (2011) 138-157.

[8] C. Y. C. Wang, C. C. Ng, C. C. Chen, T. W. Shyu, Y. T, Int J Syst Evol Microbiol, 58 (2008).
[9] C. Y. N. Wang, C. C. Tzeng, W. S. Shyu, Y. T, Int J Syst Evol Microbiol, 59 (2009).

[10] S. Asad, M. A. Amoozegar, A. A. Pourbabaee, M. N. Sarbolouki, S. M. Dastgheib, Bioresource technology, 98 (2007) 2082-2088.

[11] J. Z. Guo, J. Wang, D. Tian, C. Wang, P. Uddin, M. S, Biodegradation, 19 (2008).

[12] N. Dafale, N. N. Rao, S. U. Meshram, S. R. Wate, Bioresource technology, 99 (2008) 2552-2558.

[13] H. S. P. Hyung Joo Kim, Moon Sik Hyun, In Seop Chang, Mia Kim, B. H. Kim, Enzyme and Microbial Technology, 30 (2002).

[14] Y. Sharma, B. Li, Bioresource technology, 101 (2010) $1844-1850$.

[15] C. H. Chen, C. F. Chang, S. M. Liu, Journal of hazardous materials, 177 (2010) 281-289.

[16] D. M. Cao, X. Xiao, Y. M. Wu, X. B. Ma, M. N. Wang, Y. Y. Wu, D. L. Du, Bioresource technology, 136 (2013) 176-181.

[17] K. Han, P. L. Yueh, L. J. Qin, C. C. Hsueh, B. Y. Chen, Bioresource technology, 196 (2015) 746-751.

[18] B. Y. Chen, C. C. Hsueh, W. -M. Chen, W. D. Li, Journal of the Taiwan Institute of Chemical Engineers, 42 (2011) 816-825.

[19] B. Y. Chen, M. M. Zhang, Y. Ding, C. T. Chang, Journal of the Taiwan Institute of Chemical Engineers, 41 (2010) 682-688.

[20] B. Y. Chen, Y. M. Wang, I. S. Ng, Bioresource technology, 102 (2011) 1159-1165.

[21] B. Y. Chen, Y. M. Wang, I. S. Ng, S. Q. Liu, J. Y. Hung, Journal of bioscience and bioengineering, 113 (2012) 502-507.

[22] B. Y. Chen, C. C. Hsueh, S. Q. Liu, I. S. Ng, Y. M. Wang, Bioresource technology, 145 (2013) 321-325.

[23] B. Xu, B. Y. Chen, C. C. Hsueh, L. J. Qin, C. T. Chang, Bioresource technology, 163 (2014) 280-286.

[24] B. Y. Chen, B. Xu, P. L. Yueh, K. Han, L. -J. Qin, C. ${ }^{-C}$. Hsueh, Journal of the Taiwan Institute of Chemical Engineers, 51 (2015) 63-70.

[25] B. Y. Chen, M. M. Zhang, C. T. Chang, Y. Ding, K. L. Lin, C. S. Chiou, C. C. Hsueh, H. Xu, Bioresource technology, 101 (2010) 4737-4741.

[26] C. C. Hsueh, B. Y. Chen, C. Y. Yen, Journal of hazardous materials, 167 (2009) 995-1001. 
[27] M. M. Zhang, W. M. Chen, B. Y. Chen, C. T. Chang, C. C. Hsueh, Y. Ding, K. -L. Lin, H. Xu, Bioresource technology, 101 (2010) 2651-2656.

[28] 0. Lefebvre, R. Moletta, Water research, 40 (2006) 3671-3682.
[29] Y. Hong, M. Xu, J. Guo, Z. Xu, X. Chen, G. Sun, Applied and environmental microbiology, 73 (2007) 64-72.

[30] Y. Liu, W. Gao, Y. Wang, L. Wu, X. Liu, T. Yan, E. Alm, A. Arkin, D. K. Thompson, M. W. Fields, J. Zhou, J Bacteriol, 187 (2005) 2501-2507. 